\title{
Chile, Colombia, México y Perú: la Alianza del Pacífico
}

\author{
Daniel Rojas Lozano \\ (drojas@icesi.edu.co)
}

PASTRANA, E. y GEHRING, H. (eds.) (2014). Alianza del Pacífico: mitos y realidades. Cali: Editorial Universidad Santiago de Cali. 620 pp.

La Alianza del Pacífico (AP) es hoy en día uno de los proyectos de integración regional que más interés genera, ya sea por sus ambiciosos objetivos en la región y frente al Asia-Pacífico, ya sea por el impacto que pueda llegar a tener sobre otros proyectos regionales como ALBA, Mercosur y Unasur. En este sentido, la Alianza se constituye como un tema de interés para la comunidad académica, empresarios, actores políticos y para todos aquellos que vean en la Cuenca del Pacífico un espacio para el desarrollo económico sudamericano y para la inserción en el Asia-Pacífico, aspectos liderados en este caso por Chile, Colombia, México y Perú, países que, de acuerdo a cifras publicadas en el sitio web de la Alianza del Pacífico, representan el 38\% del PIB de América Latina y el Caribe, concentran el 50\% del comercio total y atraen el $45 \%$ de la inversión extranjera directa. ${ }^{1}$

No obstante el interés por la Alianza, pocos trabajos académicos se han desarrollado hasta ahora en torno al tema, es por eso que el libro Alianza del Pacifico: mitos y realidades se constituye como un valioso insumo para la aproximación a este reciente proceso de integración, pues reúne 18 artículos de diferentes autores que indagan en múltiples temas desde diversas perspectivas. El libro fue editado por Eduardo Pastrana,

1 Cifras tomadas del sitio web de la Alianza del Pacífico, consultado el 14 de septiembre del 2015 en: https://alianzapacifico.net/que-es-laalianza/\#valor-estrategico 
doctor en Derecho de la Universidad de Leipzig (Alemania) y actual Director del Departamento de Relaciones Internacionales de la Universidad Javeriana de Bogotá (Colombia) y por Hubert Gehring, doctor en estudios de agronomía de la Universidad Stuttgart Hohenheim (Alemania) y actualmente director de la Fundación Konrad Adenauer en Bogotá.

\section{Estructura del libro}

Pastrana y Gehring inician el libro enmarcando la Alianza del Pacífico en una 'coyuntura volátil', es decir, en un momento en el que la región se debate entre diferentes opciones económicas e ideológicas de integración. Por lo tanto, la estructura del libro busca ofrecer un análisis de los impactos que la Alianza puede tener sobre otros procesos de integración a nivel regional y global. Igualmente, el libro pretende definir la forma, extensión y profundidad de esta Alianza. En este sentido, el libro se divide en cinco partes. En la primera parte (i. Enfoque teórico), se ofrece una aproximación teórica a partir de dos capítulos. En el primero de ellos (Análisis de política exterior en el marco de procesos de regionalización: interrogantes que plantea la creación de la Alianza del Pacífico), los autores se proponen como objetivo establecer los factores domésticos y externos que dan forma a la política exterior, para así comprender por qué los miembros de la Alianza del Pacífico optan por este mecanismo de acción externa y no por otros alternativos.

Una vez se discuten los diferentes enfoques teóricos que abordan la política exterior como resultado (output) de la interacción entre el sistema intrasocietal (factores domésticos) y extrasocietal (factores externos), se dejan planteados una serie de interrogantes que giran alrededor de la comprensión de la Alianza como un producto de política exterior. Si bien este capítulo se desarrolla con un considerable nivel de abstracción, el segundo y último capítulo de esta primera parte logra presentar realidades y retos concretos que enfrenta la Alianza en su intención de consolidarse como proceso de integración innovador. Entre la soberanía, el liberalismo y la innovación: un marco conceptual para el análisis de la Alianza del Pacífico, sintetiza las definiciones de 'regionalismo' e 'integración regional' en los proyectos regionales latinoamericanos, enfocándose en los conceptos de 'soberanía', 'liberalismo' e 'innovación’. A partir de este ejercicio, los 
autores argumentan que el ceder poder soberano a organismos comunes mediante la integración, ha constituido el mayor reto para los países latinoamericanos, que al no haber consolidado su soberanía interna, no han encontrado posible ceder soberanía externa. En cuanto al liberalismo, los autores afirman que los proyectos regionales latinoamericanos siempre se han construido alrededor de esta doctrina económica, ya sea rechazándola o adhiriéndose a ella. Finalmente, frente a la innovación, los autores señalan que si bien es innovador establecer como objetivo la inserción económica en una región específica (Asia-Pacífico), no hay claridad en por qué liberalizar los flujos económicos de un grupo de países puede facilitar la consecución de este objetivo.

Esta primera parte permite entonces abordar la Alianza del Pacífico como un mecanismo colectivo de política exterior, enmarcado en un regionalismo estratégico que sigue girando alrededor del liberalismo económico.

En la segunda parte del libro (iii. Estructura institucional de la Alianza del Pacífico), se describe la estructura institucional de la Alianza, las implicaciones que tiene la 'integración profunda' pretendida por ella y la nueva configuración interregional a la que da pie. En cuanto a la estructura institucional, se argumenta que si bien la AP es una organización intergubernamental cuyas decisiones requieren del consentimiento de los Estados para vincularlos y busca actuar como un ente autónomo para promover iniciativas y lineamientos de acción sobre temas de interés regional e internacional, por ahora no es más que una zona de libre comercio, pues no cuenta con entes decisorios supranacionales, hecho que también limita la 'integración profunda' promovida por la Alianza.

Esta segunda parte, además, resalta la contradicción presente en el objetivo de la Alianza de fomentar un 'regionalismo abierto', ya que los acuerdos económicos entre miembros de la Alianza terminan discriminando a terceros con fundamento en las normas de origen. Por otro lado, en La Alianza del Pacífico y el ocaso de la Comunidad Andina: una nueva configuración interregional en Latinoamérica, se argumenta que iniciativas como la Comunidad Andina de Naciones (CAN) pierden terreno como plataformas de integración regional e internacional frente a la Alianza del Pacífico. No obstante, es necesario 
precisar que esta pérdida de terreno se produce más por el rezago de la CAN para implementar medidas como el arancel externo común y la unión aduanera, que como consecuencia de la AP. Una situación diferente se presenta con el proceso de integración impulsado por Brasil, Mercosur, pues si bien ambos bloques comerciales coexisten en la región, la AP entorpece la idea de 'suramericanismo' de Brasil al traer a México a la región, país en el que Estados Unidos ejerce una importante influencia. En este sentido, la AP implica un soft balance ante la influencia de Brasil en la región y da forma a un nuevo equilibrio interregional.

La tercera parte del libro (iii. $L a$ Alianza del Pacifico y su contexto regio$n a l$ ), ahonda más en el contexto regional en el cual se desarrolla la AP. En esta sección, diferentes autores ofrecen una lectura de la AP a partir de estudios de casos concretos, no en vano es la sección más amplia del libro, pues en siete capítulos se abordan no solamente las perspectivas de los Estados miembros de la AP sino que también se indaga acerca de las implicaciones de la AP sobre las pretensiones de liderazgo de Brasil, los retos de Venezuela frente a esta alianza y las posibilidades de una convergencia o no de los países latinoamericanos en el marco de la AP.

Las diferentes perspectivas desarrolladas por los autores en esta sección terminan invitando a debatir y cuestionar cualquier sentido unidimensional de los cuatro miembros de la Alianza en torno a ella. En este sentido, mientras que para Chile la AP es una plataforma de interacción que permite consolidarse como 'país-puente' entre la región del Asia-Pacífico y Suramérica y contrastar así la imagen de país alejado de las dinámicas regionales, para Colombia es una estrategia para acoplarse al mundo multipolar, aproximarse estratégicamente al Asia-Pacífico sin afectar su histórica relación con los Estados Unidos y además, ingresar al Foro de Cooperación Económica Asia-Pacífico (APEC por sus siglas en inglés) y al Acuerdo Transpacífico de Cooperación Económica (TPP por sus siglas en inglés), acuerdos ambos de los que ya hacen parte los otros países miembros de la AP.

México por su parte, espera que la AP sea la reedición de la fallida propuesta estadounidense de conformar un área de libre comercio para todas las américas y espera también que esta alianza limite el 
ascenso de Brasil como líder regional y facilite su regreso a la región sudamericana. Para Perú, principal promotor de la AP, esta alianza no solo significa consolidarse en el Pacífico sudamericano sino que también demuestra el liderazgo de la élite política exterior peruana y la coherencia de intereses para alcanzar un mejor posicionamiento en el Pacífico.

Estas diferentes perspectivas tienen como interés común la inserción al AsiaPacífico, y para los casos chileno y colombiano, la consolidación de cada uno de estos países como 'país-puente' entre el Asia-Pacífico y Sudamérica. Sin embargo, en esta tercera parte también se resaltan algunos límites que el mismo contexto regional supone para la alianza. Uno de estos límites es que los tres países sudamericanos tienen una muy baja conectividad debido a la deficiente infraestructura vial, especialmente en el caso colombiano, aspecto que puede llegar a dificultar la formación de cadenas de valor entre estos países.

Ya desarrolladas las diferentes perspectivas e implicaciones de la AP para cada país miembro, la tercera parte del libro se pregunta si esta alianza es una estrategia de impugnación a Brasil y cuáles son los posibles escenarios entre la AP y
Mercosur, acuerdo de integración liderado por Brasil. También se señalan algunos retos de Venezuela frente a la AP, en donde vale la pena destacar que, según los autores del capítulo Los retos de Venezuela ante la Alianza del Pacífico, la AP no es una amenaza económica para la alianza liderada por Venezuela -Alianza Bolivariana para los Pueblos de Nuestra América (ALBA)-, porque los miembros de esta segunda pueden mantener tratados comerciales con otros países; $\sin$ embargo, la AP es un reto para el poder opuesto al neoliberalismo que Venezuela busca construir en la región.

Finalmente, en esta tercera parte del libro se expone el riesgo de fragmentación regional entre el Pacífico y el Atlántico. Ante este riesgo, la autora de Alianza del Pacífico: de la fragmentación a la convergencia en América Latina, propone identificar los temas que AP y Mercosur pueden trabajar juntos y que facilitarían así una mayor unidad en la región.

La cuarta parte del libro (iv. La Alianza del Pacífico frente al globo), trae al análisis importantes actores en el plano internacional: China, la Unión Europea y Estados Unidos. En cuanto a China, el capítulo China y la Alianza del Pacífico: 
los limitantes de los roles en el proceso de construcción mutua, describe las relaciones comerciales y políticas entre el país asiático y los miembros de la AP, y además, expone la visión que China tiene de América Latina y el Caribe y la visión que los países miembros de la AP tienen de la región Asia-Pacífico, de China y de la misma AP. De acuerdo a este capítulo, claramente fundamentado en el constructivismo, ninguno de los cuatro miembros de la AP ve a China como un actor global que pueda incidir en la construcción del sistema internacional, y aunque ven la AP como puerta de entrada al mercado latinoamericano y estadounidense, terminan concibiendo dicha alianza como un instrumento individual, desligándola así de cualquier rol grupal con posible incidencia en asuntos internacionales.

En cuanto a la Unión Europea (UE), esta cuarta parte del libro incluye trabajos que argumentan que la UE concibe la AP como un nuevo centro de poder en el mundo, con afinidad económica y comercial, lo cual implica una mayor facilidad para promover el comercio libre y abierto en América Latina. Por otro lado, la democracia, estabilidad y economía de mercado en cada uno de los países miembros de la alianza, facilita el flujo de inversión europea en la región y supone un contrapeso a las políticas proteccionistas de organismos como el ALBA.

Por el lado de Estados Unidos, en el capítulo El papel de Estados Unidos frente a la Alianza del Pacífico: nuevas formas de injerencia y disuasión, se argumenta que este país nunca ha sido indiferente a los procesos de integración latinoamericanos, siempre ha buscado promoverlos o disuadirlos. En este sentido, promover la AP permitiría expandir su influencia en la región y contrarrestar el avance de China, sin embargo, participar como miembro permanente implicaría, entre otras cosas, la libre circulación de personas, pero mientras el narcotráfico sea un significativo problema para Colombia, México y Perú, su participación como miembro permanente parece poco probable. Además, Estados Unidos mantiene buenas relaciones comerciales con los países de la AP e incluso tiene tratados de libre comercio con cada uno de ellos, de manera que no tendría razones de peso para buscar ingresar a la AP.

En la quinta y última parte del libro (v. Desafios para la seguridad en la Alianza del Pacífico), se aborda el tema de cooperación en la lucha contra las drogas y el crimen transfronterizo entre los miem- 
bros de la AP y el tema del narcotráfico y el lavado de activos. En los dos capítulos que conforman esta última parte se resalta que la AP no ha incluido, hasta el momento, el tema de drogas y el de crimen transfronterizo en su agenda, sin embargo, se espera que los temas de criminalidad, y en particular el narcotráfico, lleve a promover la cooperación multilateral, especialmente por las implicaciones que tiene el narcotráfico en Colombia.

Por otro lado, se advierte que la libre circulación de personas puede conllevar a un incremento de las actividades criminales transnacionales, por lo que se requiere un compromiso de la AP para coordinar las medidas de prevención y contención de la delincuencia organizada.

\section{Comentarios}

Alianza del Pacífico: mitos y realidades, si bien recopila diferentes trabajos relacionados con la AP y sus países miembros, logra dejar señalados, a manera de advertencia, algunos temas transversales a los cuatro países, temas cuya relevancia para los actores interesados en la AP, sean académicos, empresarios o dirigentes políticos, no debería pasar desapercibida. Algunas de estas advertencias son: la necesidad de formar cadenas productivas entre Chile, Colombia, México y Perú para generar valor agregado y evitar la reprimarización productiva. Una segunda advertencia, relacionada con la primera, es la oportunidad que representa la AP para trascender de las exportaciones de commodities y lograr llevar a los mercados del Asia-Pacífico productos manufacturados. Como tercer tema o advertencia está la importancia de superar el enfoque meramente económico de la AP hacia la región Asia-Pacífico y en particular hacia China en el marco del regionalismo abierto que promueve la AP.

Además de lo anterior, el mismo contenido de los artículos recopilados en el libro deja entrever los pocos resultados que la AP ha generado por sí misma, pues el hecho de que ni siquiera hayan datos agregados de los países miembros de la AP, es un indicio de que hasta ahora los avances o retrocesos en materia de comercio exterior, flujos de inversiones e incluso acuerdos de cooperación en temas de seguridad transfronteriza, han sido más resultado de esfuerzos individuales por parte de estos Estados que resultados de negociaciones y acuerdos en bloque frente a otros actores en el plano internacional. 
Sin embargo, es importante recordar que la AP es un acuerdo relativamente nuevo, incluso Colombia ratificó el acuerdo marco de la AP en el 2014, de manera que los resultados de la AP como bloque están todavía por verse y su potencial no ha pasado aún del mito a la realidad. 